\title{
Outcome of Pregnancy with History of Previous Cesarean Section
}

\author{
${ }^{1}$ Reena J DSouza, ${ }^{2}$ Bandeppa H Narayani, ${ }^{3}$ Smitha B Rao
}

\begin{abstract}
In modern obstetric practice, pregnancy with history of previous cesarean section is quite common. A cesarean section poses some documented risks to the mother's health in subsequent pregnancies like placenta previa or accreta and uterine scar rupture. It is also associated with increased likelihood of preterm delivery, low birth weight, and perinatal death. Repeat cesarean section is technically difficult and there is chance of injury to surrounding structures. The retrospective study was done in Yenepoya Medical College Hospital during the period of January 2014 to January 2015 to find out the maternal antepartum and intrapartum complications as well as perinatal outcome in patients with a history of cesarean section. A total number of 143 pregnant patients with history of one or more cesarean section who underwent repeat cesarean sections were included. Previous classical cesarean, extreme prematurity, and those who opted for vaginal birth after cesarean (VBAC) were excluded. Mean age of the study population was 27.4 years. Here, 72.12 and $20.98 \%$ cases had history of previous one and two cesarean sections respectively. Important antepartum complications were placenta previa (3.50\%), scar tenderness (8.39\%), gestational diabetes mellitus (GDM; 4.90\%), pregnancy-induced hypertension (PIH; 6.99\%), etc. There were extensive peritoneal and bladder adhesions in 13.99 and $16.78 \%$ cases respectively, causing much preoperative difficulties and in one case urinary bladder was injured during operation. Postoperative period was uneventful in $72.72 \%$ cases. In this study, $20.28 \%$ neonates developed some complications like prematurity, low birth weight, birth asphyxia, and neonatal jaundice. Here the rate of perinatal mortality was $1.4 \%$.
\end{abstract}

Keywords: Cesarean section, Perinatal mortality, Placenta previa, Scar tenderness, Urinary bladder.

How to cite this article: DSouza RJ, Narayani BH, Rao SB. Outcome of Pregnancy with History of Previous Cesarean Section. J South Asian Feder Obst Gynae 2017;9(4):308-311.

Source of support: Nil

Conflict of interest: None

Date of received: 6 October 2017

Date of acceptance: 29 November 2017

Date of publication: January 2018

\footnotetext{
${ }^{1}$ Assistant Professor, ${ }^{2,3}$ Associate Professor

${ }^{1-3}$ Department of Obstetrics and Gynecology, Yenepoya University Mangaluru, Karnataka, India
}

Corresponding Author: Bandeppa H Narayani, Associate Professor, Department of Obstetrics and Gynecology, Yenepoya University, Mangaluru, Karnataka, India, Phone: +919738566860 e-mail: bandi_dd@yahoo.com

\section{INTRODUCTION}

Cesarean birth has been a major source of interest and concern over the last few decades. In the past 35 years, the rate of cesarean section has steadily increased from $5 \%$ to approximately $25 \% .{ }^{1}$ So pregnancy with history of previous cesarean section is prevalent in present-day obstetric practice. Precise quantification of the risk attributable to a prior cesarean section is difficult. It has been associated with increased risk of placental abruption and placenta previa in subsequent pregnancies, conditions resulting in increased likelihood of preterm delivery, low birth weight, and perinatal death.

A retrospective analysis of catastrophic complication of previous cesarean section by Cynthia Chagotte ${ }^{2}$ showed that $2.4 \%$ of the patients after one or more cesarean section had an extremely serious complication like uterine rupture and placenta previa or accreta with accompanying hemorrhage. Other complications like impending rupture, bladder discomfort, preterm delivery, operative interference, and incidental morbidity can occur during pregnancy, labor and in repeat cesarean section. ${ }^{3}$ There are more technical difficulties and increased chance of injury to the surrounding structures during repeat C-section and postoperative complications are likely to be increased. ${ }^{4}$ The risk of injury to bladder is increased threefold in repeat cesarean section. ${ }^{5}$ Although maternal mortality after scar rupture is low, the major risk is to the fetus that can suffer from anoxic brain damage or die if not delivered very urgently. This study was designed to find out the maternal antepartum and intrapartum complications as well as perinatal mortality and morbidity in patients with history of previous cesarean section.

\section{AIMS AND OBJECTIVES}

- To find out antepartum maternal complication related to previous cesarean section.

- To find out intrapartum maternal and fetal complication.

- To find out fetal outcome like prematurity, perinatal mortality and morbidity.

\section{MATERIALS AND METHODS}

This study was conducted in Yenepoya Medical College Hospital, a tertiary care referral center in rural part of 
Karnataka (Southern India). Retrospective analysis of medical records of 143 women with previous one or two cesarean section who delivered during the time period January 2014 to January 2015 was carried out.

The exclusion criteria included women with previous classical cesarean section, those with extreme prematurity (less than 32 weeks), and those who opted for VBAC.

Data were collected by preparing a data collection sheet, which included the patient's particulars, antepartum clinical, laboratory, and intrapartum or peioperative, postoperative findings as well as perinatal outcome of the fetus. Collected data were compiled and analyzed using Statistical Package for the Social Sciences statistical package.

\section{RESULTS}

During the study period, January 2014 to January 2015, a total number of 143 pregnant patients were included in this study who were admitted with history of one or more cesarean sections. The mean age of the study population was 27.4 years $(<20-40) ; 76.22 \%$ cases were aged 21 to 30 years (Table 1 ).

All the study populations were multigravida having various types of previous obstetrical history. Graph 1

Table 1: Age incidence of study population

\begin{tabular}{llll}
\hline Age in years & $\begin{array}{l}\text { Number of } \\
\text { patients }\end{array}$ & Percentage & Mean age \\
\hline$<20$ & 3 & 2.10 & \\
$21-25$ & 38 & 26.57 & \\
$26-30$ & 71 & 49.65 & 27.4 years \\
$31-35$ & 22 & 15.38 & \\
$36-40$ & 7 & 4.90 & \\
41 and above & 2 & 1.40 & \\
\hline Total & 143 & & \\
\hline
\end{tabular}

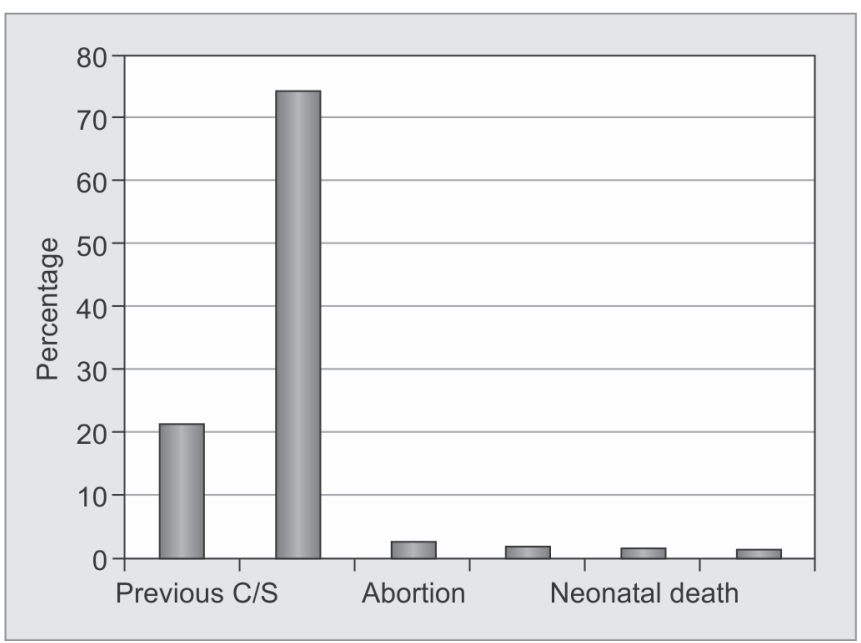

Graph 1: Obstetric history shows that $74.12 \%$ patients had one and $20.98 \%$ had two previous C-sections.

Majority $(74.82 \%)$ of the cases were admitted with term, only $13.99 \%$ were with preterm, but $11.19 \%$ with postdatism (Graph 2).

Table 2 reveals that in more than half of the cases antepartum period was uneventful. Another $17.48 \%$ cases had some complications related with previous surgery like placenta previa, scar tenderness, chronic abdominal pain. In $16.79 \%$ cases there were some medical disorders like GDM, PIH, urinary tract infection, etc.

Among the study population, $46.15 \%$ needed emergency cesarean section and the rest $(53.85 \%)$ of the cases were terminated on elective basis by cesarean section. Only $5.59 \%$ cases required blood transfusion during operation.

Table 3 shows that in $13.99 \%$ cases extensive peritoneal adhesion with uterus and posterior surface of anterior abdominal wall and bladder was adherent in $16.78 \%$ cases .

Postoperative complications are shown in Table 4. Here majority $(72.72 \%)$ had no complication. Important complications were wound infection $(7.69 \%)$, anemia (3.50), postpartum hemorrhage (PPH; $1.40 \%)$, etc.

Table 2: Antepartum complications

\begin{tabular}{lll}
\hline Problems & Number & Percentage \\
\hline $\begin{array}{l}\text { No complication } \\
\text { Complications related with previous } \\
\text { surgery }\end{array}$ & 94 & 65.73 \\
Placenta previa & 5 & \\
Chronic abdominal pain & 8 & 3.50 \\
Scar tenderness & 12 & 5.59 \\
Medical disorders & & \\
GDM & 7 & 4.39 \\
PIH & 10 & 6.99 \\
UTI & 4 & 2.80 \\
Respiratory disease/cardiac disease & 0 & \\
Fibroid uterus & 3 & 2.10 \\
\hline
\end{tabular}

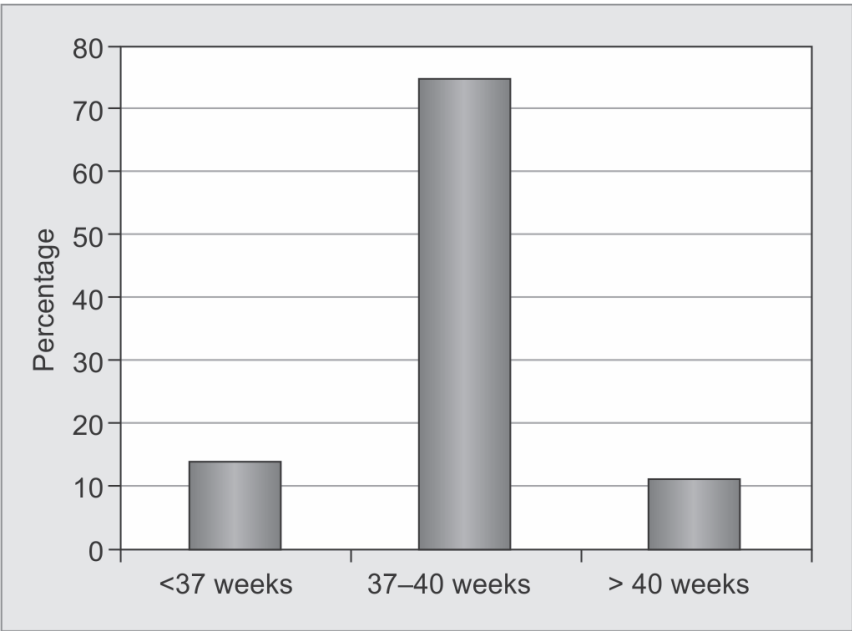

Graph 2: Period of gestation 
Table 3: Types of intraoperative problems

\begin{tabular}{|c|c|c|}
\hline Types of problems & Number & Percentage \\
\hline \multicolumn{3}{|l|}{$\begin{array}{l}\text { Difficulty in opening the abdomen due } \\
\text { to adhesion }\end{array}$} \\
\hline - minimal adhesion & 58 & 40.56 \\
\hline - extensive adhesion & 20 & 13.99 \\
\hline - no adhesion & 65 & 45.45 \\
\hline $\begin{array}{l}\text { Difficulty to reach lower segment due } \\
\text { to adhesion with bladder }\end{array}$ & 24 & 16.78 \\
\hline Bladder injury & 1 & 0.70 \\
\hline $\begin{array}{l}\text { Difficulty in stitching the uterine incision } \\
\text { due to extreme thinning }\end{array}$ & 15 & 10.49 \\
\hline Impending rupture & 2 & 1.40 \\
\hline
\end{tabular}

Table 5: Perinatal fetal outcome

\begin{tabular}{lll}
\hline Condition of baby & Number of cases & Percentage \\
\hline Healthy & 114 & 79.72 \\
Birth asphyxia & 3 & 2.09 \\
Premature & 7 & 4.90 \\
IUGR & 7 & 4.90 \\
Neonatal jaundice & 8 & 5.59 \\
Neonatal infection & 2 & 1.40 \\
Neonatal death & 1 & 0.70 \\
IUD & 1 & 0.70 \\
\hline
\end{tabular}

Perinatal fetal outcome has been shown in Table 5 . Majority $(79.72 \%)$ of the babies were healthy; the rest had some complications like prematurity (4.90\%), intrauterine growth restriction (IUGR; 4.90\%), birth asphyxia $(2.09 \%)$, neonatal infection (1.4\%), and neonatal jaundice (5.59\%). Perinatal death was found in two cases, one of them was intrauterine device (IUD) and the other was early neonatal death.

\section{DISCUSSION}

In modern practice, with the objective of safe motherhood and mother baby package program the aim of obstetricians is to achieve a healthy mother and healthy baby. To achieve this goal, cesarean section plays a vital role and increasing trend of cesarean section is also related to it to a certain extent. Thus, repeat cesarean section is the commonest contributory factor for increased rate of C-section. It varies from country to country and center to center; $95 \%$ of all cesarean sections are in USA, 23\% in Norway, 24 to $30 \%$ in India, and the lowest $8 \%$ in Hungary. ${ }^{6}$

This study was done in the Department of Obstetrics and Gynaecology of Yenepoya Medical College Hospital, among 143 patients with history of one or more cesarean sections who were admitted for termination of pregnancy either on emergency or elective basis.

Majority $(76.22 \%)$ of the study population were of 21 to 30 years, which is more or less similar to other study results done in SSMC Mitford Hospital where 69.2\% cases
Table 4: Types of postoperative problems

\begin{tabular}{lll}
\hline Complications & $\begin{array}{l}\text { Number of } \\
\text { cases }\end{array}$ & Percentage \\
\hline No complications & 104 & 72.72 \\
Wound infection & 11 & 7.69 \\
Severe discharge from the wound & 9 & 6.29 \\
Puerperal pyrexia & 2 & 1.40 \\
PPH & 2 & 1.40 \\
UTI & 3 & 2.10 \\
Anemia & 5 & 3.50 \\
Headache & 5 & 3.50 \\
Postoperative rise of blood & 2 & 1.40 \\
pressure & & \\
\hline
\end{tabular}

were between 20 and 29 years. ${ }^{7}$ Here 74.12 and 20.98\% cases had history of previous one and two cesarean sections respectively. Among all patients, a significant number had history of previous pregnancy loss, e.g., spontaneous abortion $(2.10 \%)$, stillbirth $(1.4 \%)$, neonatal death $(0.7 \%)$, and other $0.7 \%$ had ectopic pregnancies.

Among the study population, there were some common complications associated with previous cesarean section like placenta previa (3.50\%), scar tenderness (8.39\%), and chronic abdominal pain (5.59\%). A significant number $(16.79 \%)$ of cases had some medical disorders like GDM, PIH, and UTI. Majority (74.82\%) cases came with term pregnancy; only $11.19 \%$ were preterm and required emergency termination for GDM, severe preeclampsia, multiple pregnancies, antepartum hemorrhage, etc. Here, total $39.86 \%$ cases underwent emergency cesarean section. The elective cesarean section is $50.35 \%$ in comparison to those of Khawaja et $\mathrm{al}^{8}$ in Pakistan (11.33\%) and Asaduzzaman ${ }^{9}$ in Bangladesh (34.6\%).

As all the patients underwent cesarean section both perioperative and postoperative findings were observed meticulously. In $13.99 \%$ cases there were extensive adhesion among uterus, omentum and anterior abdominal wall causing difficulties in opening the abdomen. Urinary bladder was found adherent in $16.78 \%$ cases and in one of them it was injured during operation. In $10.49 \%$ cases lower segment was found so thin that suturing was found difficult. The overall perioperative complication was much less $(12.1 \%)$ in the study of Bergholt and Stenderup. ${ }^{10}$

This study reveals that majority $(72.72 \%)$ cases had no postoperative complication. Here important complications were PPH (1.40\%), wound infection (7.69\%), anemia $(3.50 \%)$, etc. The rate of complication is significantly less in this study in comparison to other two studies done by Chowdhury et $\mathrm{al}^{7}$ and Asaduzzaman. ${ }^{8}$

In this study, $20.28 \%$ babies developed complications, which is statistically comparable to the study of Dey and Hatai ${ }^{11}$ in India. Among them, $4.90 \%$ babies were premature, $2.09 \%$ had birth asphyxia, and other $5.59 \%$ developed neonatal jaundice. Here number of perinatal 
mortality was two, of them one was a case of intrauterine fetal death and the other baby died in early neonatal period. These findings are a bit different from the study of Tadesse et $\mathrm{al}^{12}$ in Ethiopia where stillbirth and neonatal death were 2.8 and $4.7 \%$ respectively.

\section{CONCLUSION}

This is a very limited study which revealed that previous cesarean section-related antenatal complications were not very high, but a significant number of cases had perioperative complications. There was no maternal mortality but perinatal fetal mortality rate was $1.40 \%$. Further larger study with the scope of trial of vaginal delivery would be important to evaluate the pregnancy outcome in patients with a history of previous cesarean section.

\section{REFERENCES}

1. Incerpi $\mathrm{MH}$. Operative delivery. In:Decherney AH, editor. Current diagnosis \& treatment obstetrics \& gynecology, 10th ed. New York: McGraw-Hill Companies; 2007. pp. 461-476.

2. Chagotte C, Wayne R, Cohen M. Catastrophic complications of previous cesarean section. Am J Obstet Gynecol 1990 Sep;163(3):738-742.

3. Dutta DC. Pregnancy with history of previous cesarean section. Textbook of obstetrics including perinatology and contraception, 6th ed.; 2005:8794. pp. 345-346.
4. Crighton SM, Peace JM, Stanton SL. Complications of cesarean section. In: Progress in obstetrics and gynecology. Edinburgh: Churchill Livingstone; 1991:9. pp. 163-176.

5. Johanson R. Obstetric procedures. In: Edmands JK, editor. Dewhurst's textbook of obstet gynecol for post graduate, 6 th ed. 2000. p. 325.

6. Nasir NA. Changing trends in cesarean section. In: Ratnam SS, Rao KB, Anulkamarans editors. Obstetric and gynecology for postgraduate, 2nd ed. New Delhi: Oriental Longman Limited; 1991;1. pp. 134-140.

7. Chowdhury SB, Newaz R, Begum A, Dewan F. Indications and complications of cesarean section-a study of 1083 cases. Bangladesh J Obstet Gynecol 1994;9:1-7.

8. Khawaja NP, Yousuf T, Tayyeb R. Analysis of cesarean delivery at a tertiary care hospital in Pakistan. J Obstet Gynecol 2004 Feb;24(2):139-141.

9. Asaduzzaman K. A study on factors and outcome of cesarean section among the patients admitted in a tertiary care hospital, (Dissertation), Dhaka, Bangladesh College of Physicians and Surgeons, 1996.

10. Bergholt $\mathrm{T}$, Stenderup JK. Intra-operative surgical complication during cesarean section. Act Obstet Gynecol Scand 2003 Mar;82:251-256.

11. Dey N, Hatai SK. A study of cesarean section cases with special references to maternal and neonatal outcome. J India Med Assoc 1992 Jun;90(6):149-151.

12. Tadesse $\mathrm{E}$, Adane M, Abiyou M. Cesarean section deliveries of Tikur Anbessa Teaching Hospital, Ethiopia. East Far Med J 1999 Sep;73(9):619-622. 